\title{
Open pit numerical model calibration using a pseudo three-dimensional radar monitoring technique
}

\author{
J. Severin SRK Consulting (Canada) Inc., Canada \\ E. Eberhardt Department of Earth and Ocean Sciences, University of British Columbia, Canada
}

S. Fortin Teck Resources Ltd., Canada

\begin{abstract}
Slope monitoring plays an important role in the calibration of numerical models created to investigate the mechanics of large open pit slopes. Geodetic prisms are often relied upon to delineate the boundaries of potential slope hazards; however the data can be limited by its point-measurement nature. Localised displacements at each prism may be misinterpreted when extended to the behaviour of the entire slope, and important displacements between prisms may be overlooked. A novel experiment was conducted in which two ground-based synthetic aperture radar systems were simultaneously deployed to record continuous, line-of-sight displacement of an open pit slope in 'stereo'. The displacement vectors were combined to create a pseudo 3D displacement map of the pit slope consisting of over 25,000 monitoring points. The data collected demonstrated that an improved understanding of the 3D kinematics of a large rock slope can be achieved using advanced state-of-the-art monitoring techniques to aid mine design. The displacement data as well as the understanding of the slope kinematics were then used to calibrate a numerical model of the current pit slope created using 3DEC, a 3D distinct element modelling code. Rock mass and fault properties were modified until the response observed in the model was more representative to that of the monitoring data throughout the slope face. Rock mass response to mining-induced stress was shown to vary over several different parts of slope, including the areas adjacent to the main faults within the slope.
\end{abstract}

\section{Introduction}

Monitoring of geodetic prisms forms a key component of modern open pit slope management programs. Standard practice involves periodic measurement by a survey crew or robotic total station to identify and quantify the nature and extent of pit slope movements, and to provide early warning of an impending failure. However, as point measurements, prism monitoring is susceptible to uncertainty relating to the geological conditions and slope kinematics controlling the instability mechanism. The detection of accelerating behaviour may either be an early warning of impending failure or a false alarm related to highly localised movements in the immediate vicinity of the prism. Similarly, the interpolation of slope behaviour between prism locations may result in displacements influenced by large-scale geological structures being misinterpreted or missed all together.

Geological structures (e.g. major fault zones) often play a dominant role in controlling the kinematics and stability of large pit slopes and are largely ignored by the empirical slope stability procedures used to evaluate potential failure (Fukuzono, 1985). With the added consideration of complex stress-strain interactions in response to progressive rock mass failure, the resulting $3 \mathrm{D}$ deformation pattern of the pit slope can become difficult to interpret with respect to how it will evolve in complex slope failures. This may create a serious obstacle in the stability assessment of the slope, as shown in the caving-induced collapse of the $800 \mathrm{~m}$ high pit wall at Palabora in South Africa (Brummer et al., 2006).

In 2011, a novel experiment involving the simultaneous deployment of two ground-based interferometric synthetic aperture radar (InSAR) systems was undertaken (Severin et al., 2011). The radar units were used to collect continuous, line of sight displacement data in 'stereo' of a large, moving open pit slope bisected by a large fault. The data and results from this experiment demonstrated that pseudo-3D vectors could be 
created from the two radar data sets and that the information could be used to investigate slope kinematics in areas without geodetic monitoring points as well as an increased ability to review the displacement response to open pit mining over an entire slope. This paper extends the initial analysis previously completed by Severin et al. (2011) and builds on previous slope kinematic models created to describe the observed displacements (Rose and Scholz, 2009; Tosney et al., 2004). Information gained from the monitoring data was then used to create and modify a pit wall scale discrete element model of the Lornex Pit.

\section{$2 \quad$ Radar slope monitoring}

New developments in slope monitoring include the use of remote sensing technologies like terrestrial radar, which provide high-resolution, full area spatial coverage as opposed to relying on geodetic point measurements. The commercially available radar system used in this study, IBIS-M (manufactured by IDS Ingegneria Dei Sistemi), is based on three techniques: i) Stepped Frequency Continuous Wave (SF-CW) allowing resolution in the range direction, ii) Synthetic Aperture Radar (SAR) allowing the system to resolve the monitored region in the cross range direction, and iii) differential interferometry allowing the measurement of displacements by comparing phase information of the back scattered electromagnetic waves collected at different times. The IBIS-M system is suited for safety critical monitoring, being capable of performing real-time, near-continuous ( 5 minute interval), line-of-sight (1D) monitoring of large areas, day or night and in all weather conditions (Farina et al., 2012). Such capabilities are helping to establish radar as a key tool for managing unstable pit slopes, quickly identifying the size, extent and temporal behaviour of a developing failure (Day and Seery, 2007; Harries et al., 2006; Harries and Roberts, 2007). Rödelsperger et al. (2010) describe the advantages and disadvantages of the IBIS-M unit as compared to other forms of monitoring. One key limitation of all radar systems, relevant to this study, is that the data is line-of-sight displacement, meaning that important information of the slope kinematics may be overlooked.

\section{$3 \quad$ Radar experiment}

\subsection{Experiment location}

A unique monitoring experiment using two IBIS-M radar systems was conducted in at the Teck Highland Valley Copper (THVC) mine, located near Kamloops, Canada (Severin et al., 2011). THVC is a truck and shovel operation comprised of several large open pits. The experiment described here was carried out in the Lornex Pit (Figure 1).

The west wall of the Lornex Pit involves a $400 \mathrm{~m}$ high slope with an overall angle of $29^{\circ}$. The rock is relatively competent but is altered in the vicinity of the fault zones. The west wall is bisected by the Lornex Fault Zone (LFZ), an $80 \mathrm{~m}$ wide zone of highly fractured and intensely altered rock that dips approximately $80^{\circ}$ into the slope (Figure 1). The LFZ is interpreted as playing a critical role in controlling the kinematics of the upper slope movement. Other moderately to steeply dipping faults that trend northeast-southwest occur intermittently throughout the hanging wall of the LFZ. Movement within the hanging wall of the LFZ (upper slope) is reported as being caused by a complex toppling mechanism with a historical maximum daily velocity of greater than $300 \mathrm{~mm} /$ day (Rose and Scholz , 2009).

At the time of writing of this paper, the west wall of the Lornex Pit was well instrumented with over 75 geodetic prisms installed; however, the northwest portion of the pit wall is relatively bare of prisms (Figure 2, left), primarily because safety concerns or lack of access preventing the installation or the slope displacement has rendered them inoperative. The Lornex Pit is currently undergoing a pushback around its entire circumference. 


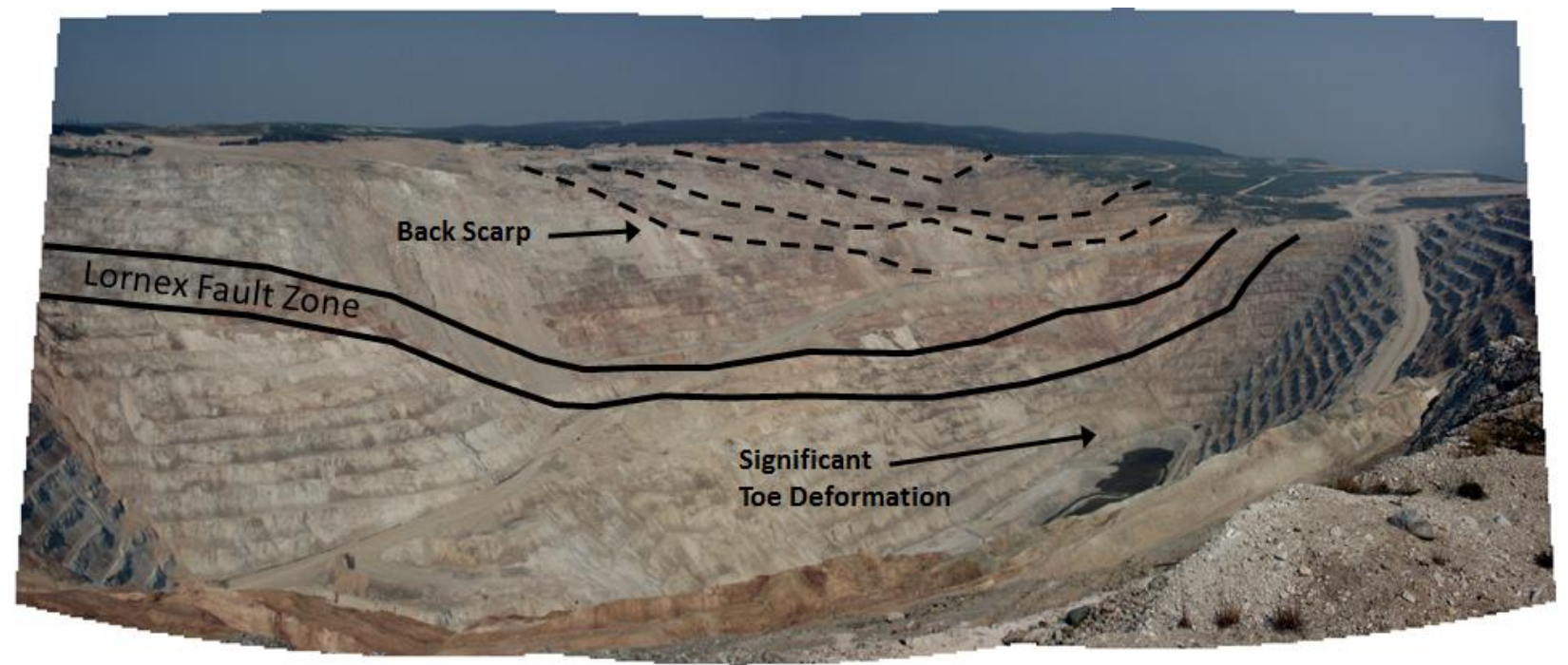

Figure 1 West wall of the Lornex Pit at the Teck Highland Valley Copper mine, showing the location of the Lornex Fault Zone, and graben-like backscarps and toe bulging that has developed with pit wall movements

The first radar unit (Site A) was located near the top of the northeast pit wall (Figure 2, right). The distance of the monitored points here ranged between approximately 800 and 1,500 m. This site was chosen for being roughly parallel to the expected direction of slope movement. The second radar unit (Site B) was located at the top of the southeast pit wall, providing good spatial overlap with Site $A$ and an oblique angle to the expected direction of slope movement. The distance of the monitored points ranged between 1,200 and $2,500 \mathrm{~m}$. Both monitoring sites were located outside the range of fly-rock generated from production blasts.
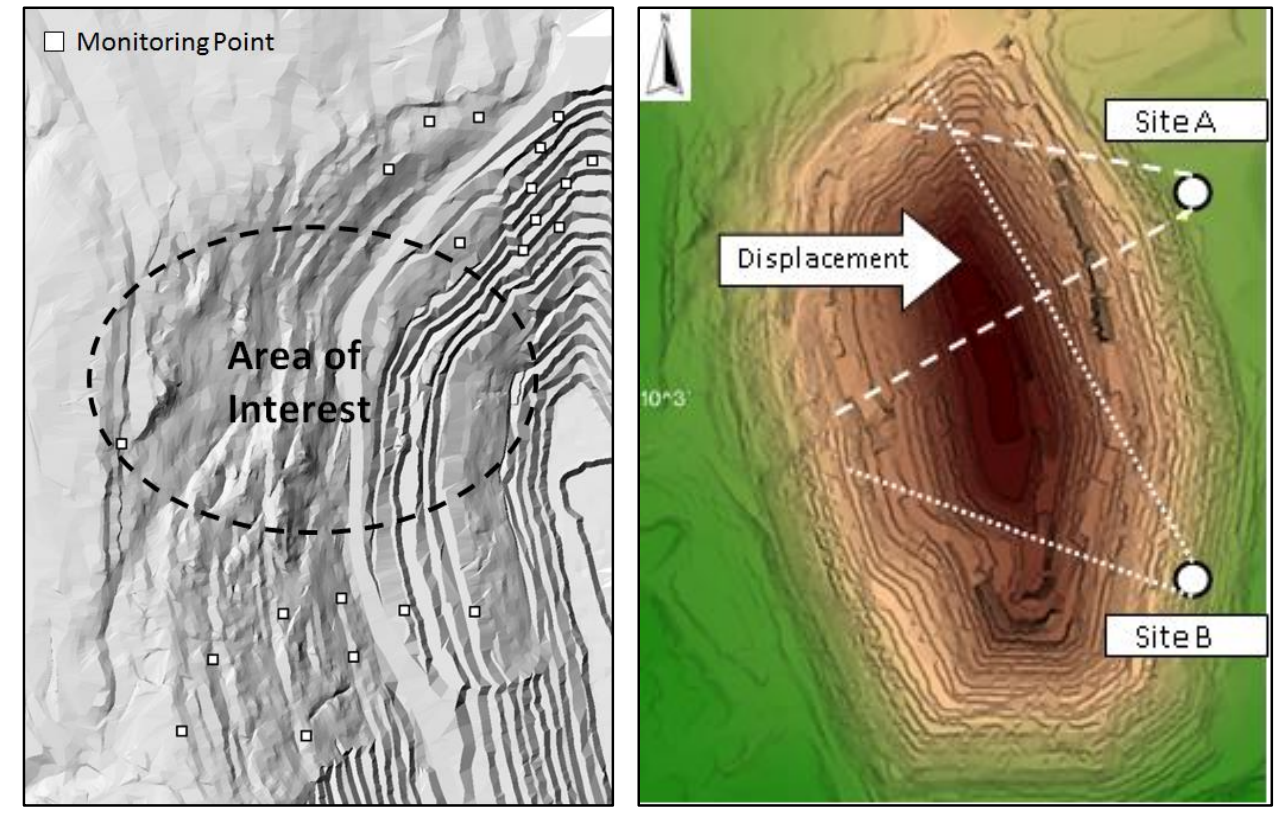

Figure 2 Location of geodetic operational prisms on the northwest wall Lornex (left) and the IBIS-M radar monitoring sites (right) with respect to the portion of the wall undergoing the highest rates of displacement (within dashed lines)

The radar units were synchronised to run simultaneously under the same conditions for several days collecting data with the same scan interval (6 minutes). The radar setup is shown in Figure 3. 

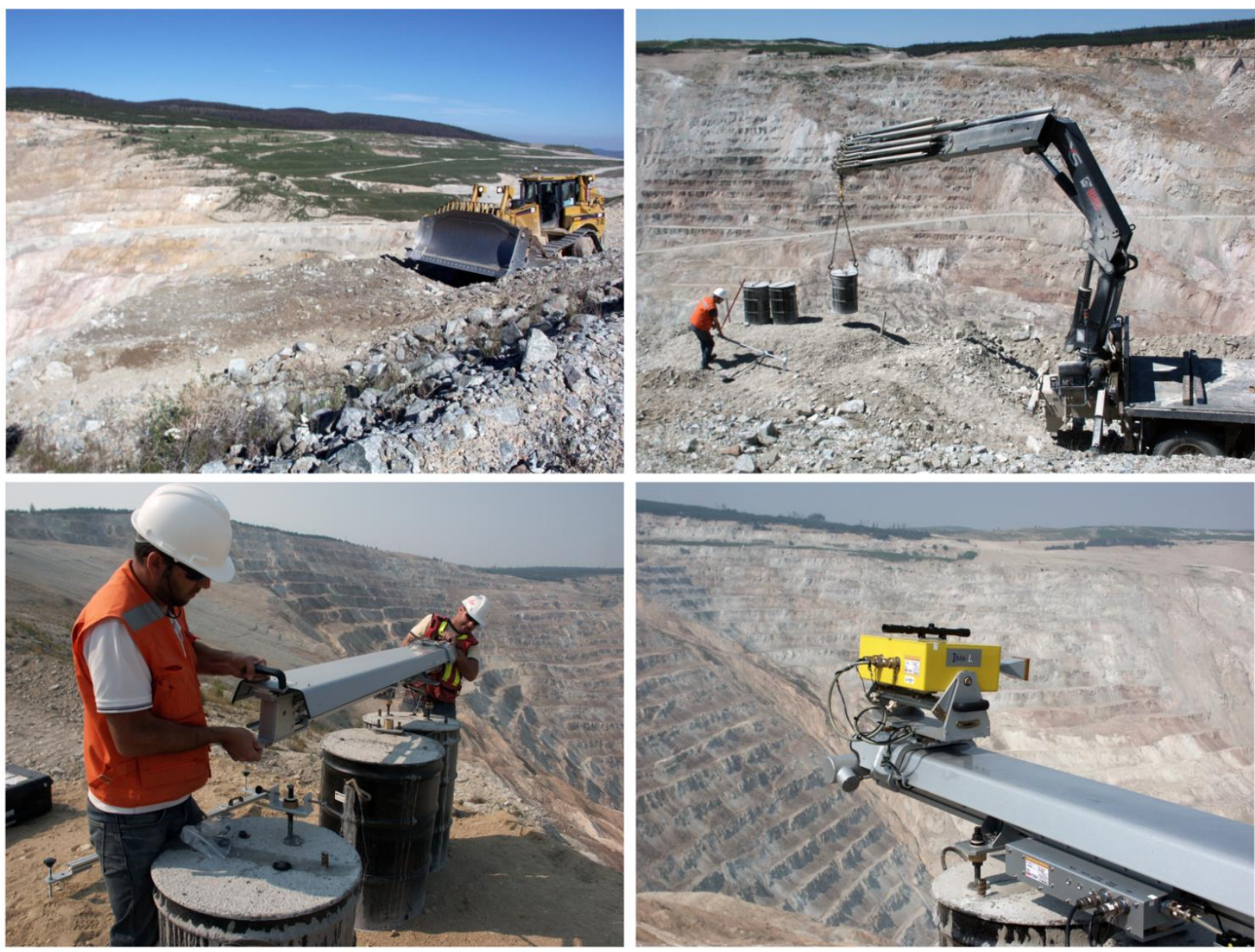

Figure 3 Site preparation and installation of the IBIS-M radar unit for the ${ }_{3}$ D radar experiment, showing: levelling and grading of site pad, lifting of concrete filled drums for radar base, fitting of levelled radar guide rail, and radar in position for pit wall monitoring

\section{$4 \quad$ Experiment results}

\subsection{Individual displacement measurements}

Two independent displacement maps for each of the installation points were created over the selected time frame. These data sets were overlain on a digital elevation model (DEM) of the mine site and converted into X, Y, Z coordinates with displacement values. Approximately 25,700 points were found to be common between the two data sets. Total cumulative displacement maps based on the individual instruments (Sites A and B) were also created for individual comparison (Figure 4). Severin et al. (2011) provide a full description of the process of combining the two data sets.

At Site A, displacement values ranged between +26 to $-220 \mathrm{~mm} /$ day, while at Site B, displacement values ranged between +35 to $-275 \mathrm{~mm} /$ day. Negative values represent movement toward the instrument, while positive values represent movement away from the instrument. The displacement patterns recorded from Sites A and B were similar with slightly different boundaries and, in some cases, magnitude. This confirms the presence of absolute movement occurring in distinct areas of the pit wall and that the different perspectives of the instrument can measure different components of that movement. 

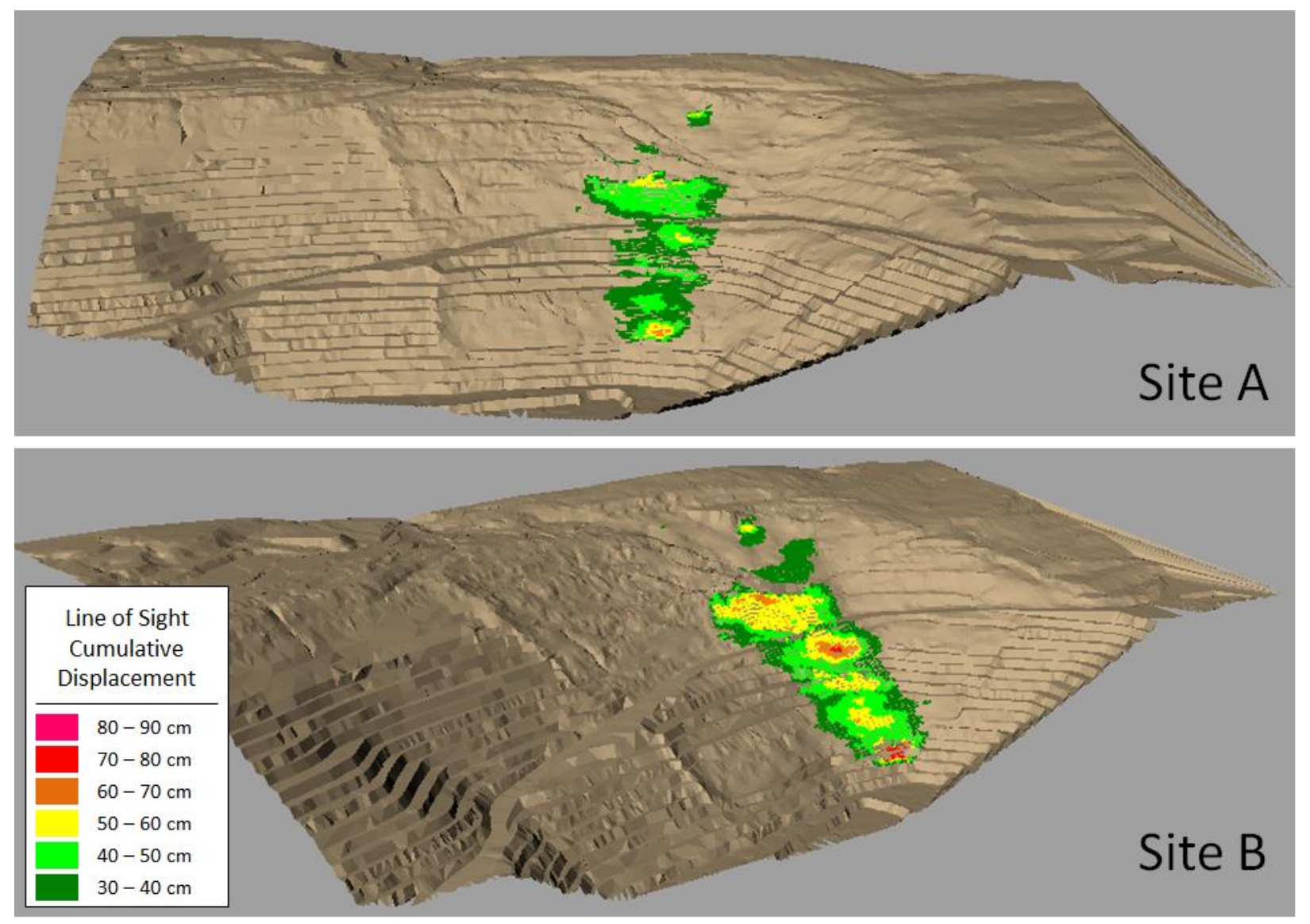

Figure 4 Radar measured line-of-sight displacement patterns from; (a) Site A; and (b) Site B. The Lornex Fault Zone is represented by the thick line bisecting the pit wall slope

\subsection{Pseudo 3D displacement pattern}

The combined displacements measured from the two radar systems provide a means of interpreting vectors in multiple 2D planes formed by the location of sites $A$ and $B$ and the target; a pseudo 3D map. The computed resultants lead to the pattern observed in Figure 5. Displacement values ranged between 0 to $307 \mathrm{~mm} /$ day and as much as $750 \mathrm{~mm}$ cumulative displacement over the monitored four day time period. These results show maximum displacement values that are higher than the $100 \mathrm{~mm} /$ day average previously reported for the geodetic prisms along the same pit wall (Rose and Scholz, 2009). Likely explanations for this discrepancy include the large number of points being measured, the opportunity to measure near vertical rock faces and areas moving too rapidly to install stable prisms, and the mining activities at the time of the experiment which may have influenced activity along the LFZ.

By creating the pseudo-3D displacement map, a more accurate representation of the location and pattern of displacements in the slope can be achieved. Based on the combined displacement pattern, several distinct zones of displacement can be observed in Figure 5, including: i) below the Lornex Fault near the base of the pit, ii) just above the LFZ near a former access ramp, and iii) in the upper reaches of the slope. The full extent of these lobes can be determined as well as smaller zones within the pit wall. The zones of concentrated displacements resolved by combining the individual radar line-of-sight displacements highlight several smaller areas of localised displacement otherwise not discernible in either of the individual displacement plots. These displacement zones can then be used, in combination with the conventional geodetic data, to help better understand the actual kinematics of the slope, the limits of movement within the slope, and help to calibrate both 2D and 3D numerical deformation models. 


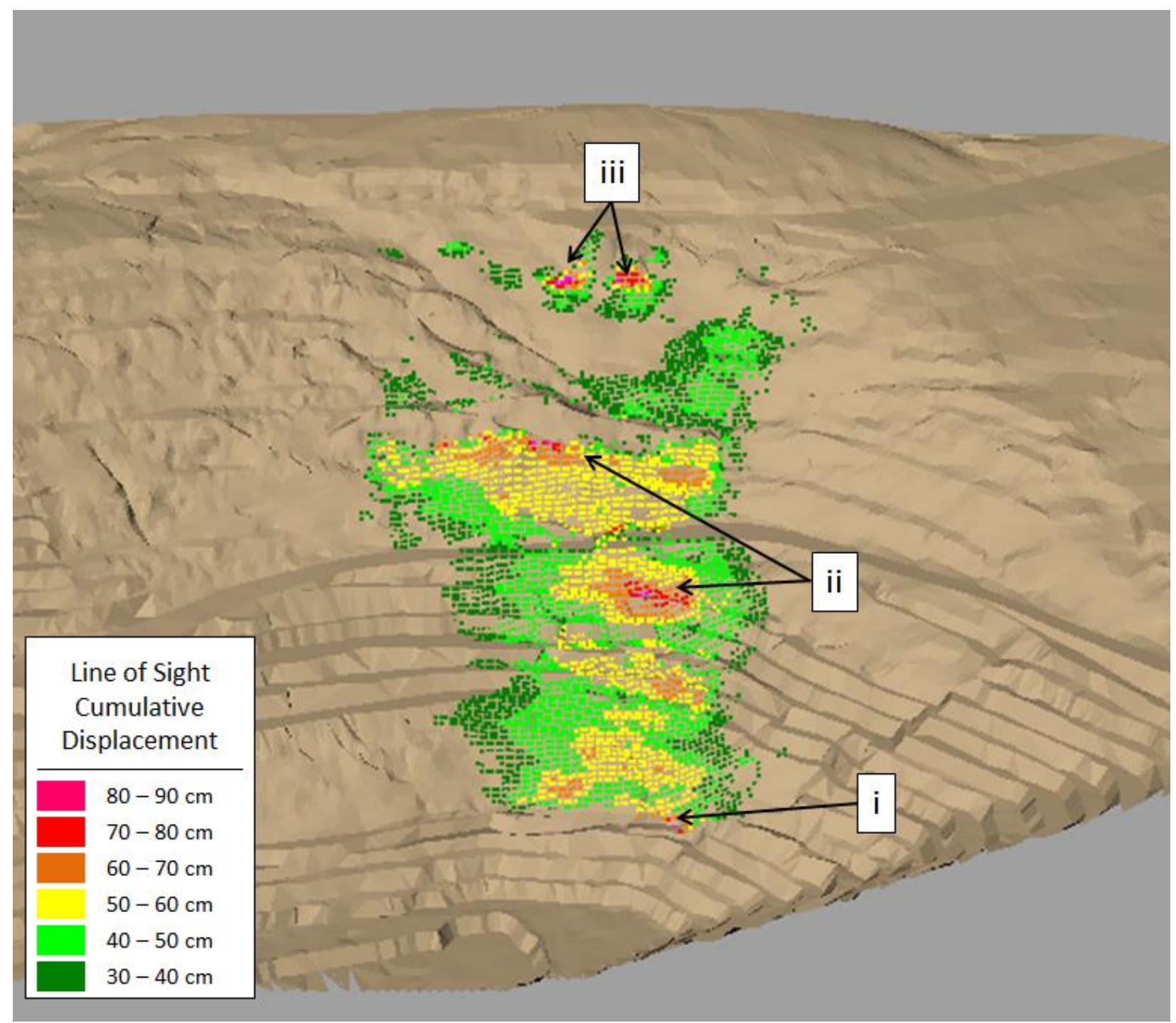

Figure 5 Combined displacement pattern from Sites A and B. Several distinct zones are identified (i, ii and iii), as described in the text

\subsection{Displacement vectors}

The displacement direction of each monitoring point can be resolved into a vector from the individual sets of radar monitoring data ( $A$ and B). The enlarged region in Figure 6 shows an example of an area with higher displacement rates in the slope. By plotting the displacement vectors, several independent lobes of movement within the slope are observed which are likely controlled by separate structures within the rock mass and changes in lithology and constitutive behaviour of the rock mass.

The vectors for both of these indicate toppling movements in the upper slope above the Lornex Fault, which agrees with the presence of a discontinuity set that dips into the slope. 


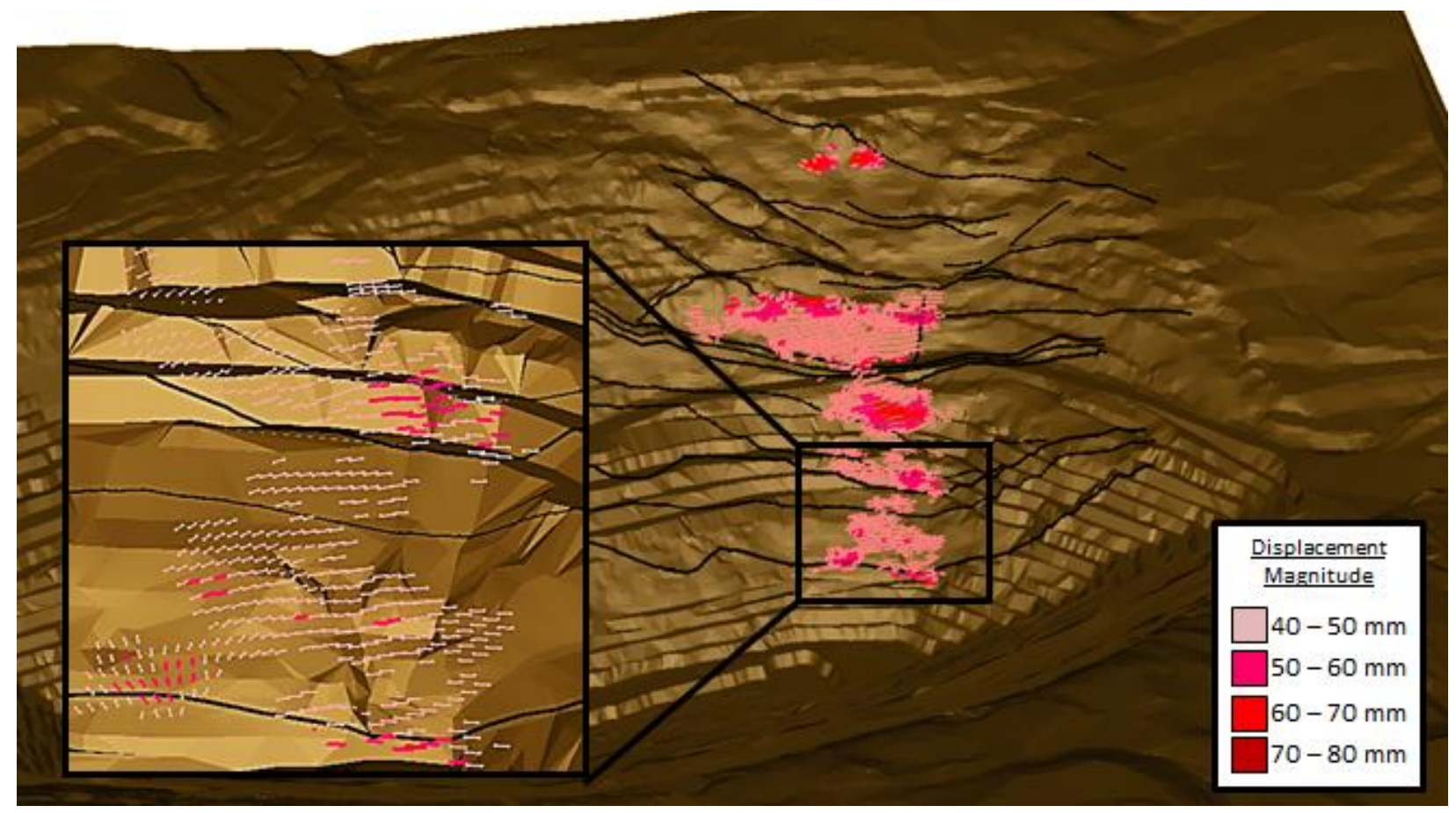

Figure 6 Combined vector map from Sites A and B, with vectors scaled to displacement magnitudes to show direction of movement. Lower diagram shows an enlarged view of the upper slope (approximately $125 \times 125 \mathrm{~m}$ )

\subsection{Potential sources of error}

Several potential sources of error during the creation of these maps were identified (Severin et al., 2011) including:

- Software rounding errors, significant only where very small displacements are recorded.

- Requirement of three radar units to create a true 3D vector.

- Configuration or placement of radar with respect to displacement direction.

\section{$5 \quad 3$ D pit slope kinematics}

Review of the combined radar displacement data (magnitude, direction, and plunge) allows for an expansion of the previous slope kinematic models (Rose and Scholz, 2009; Tosney et al., 2004). These were created to describe the observed displacements within the Lornex Pit based on field observations and geodetic data, complemented by 2D numerical analyses. Figure 7 shows projections of the 3D radar data in terms of cumulative displacement, azimuth and plunge (Figures. 7(a), (b), and (c)) of the displacement vectors.

A bias within the plunge data exists as the set up locations of both radars were placed near the pit rim, giving rise to an upward plunge in the line of sight displacement. The plunge values should only be used as a tool to help guide in the identification of possible rock displacement mechanisms and to determine areas of relative upward movement. Figure $7(\mathrm{~d})$ shows the interpreted kinematic modes based on these, which were then used to develop the $2 \mathrm{D}$ engineering geology model of the interpreted pit wall deformation mechanisms in Figure 9. 

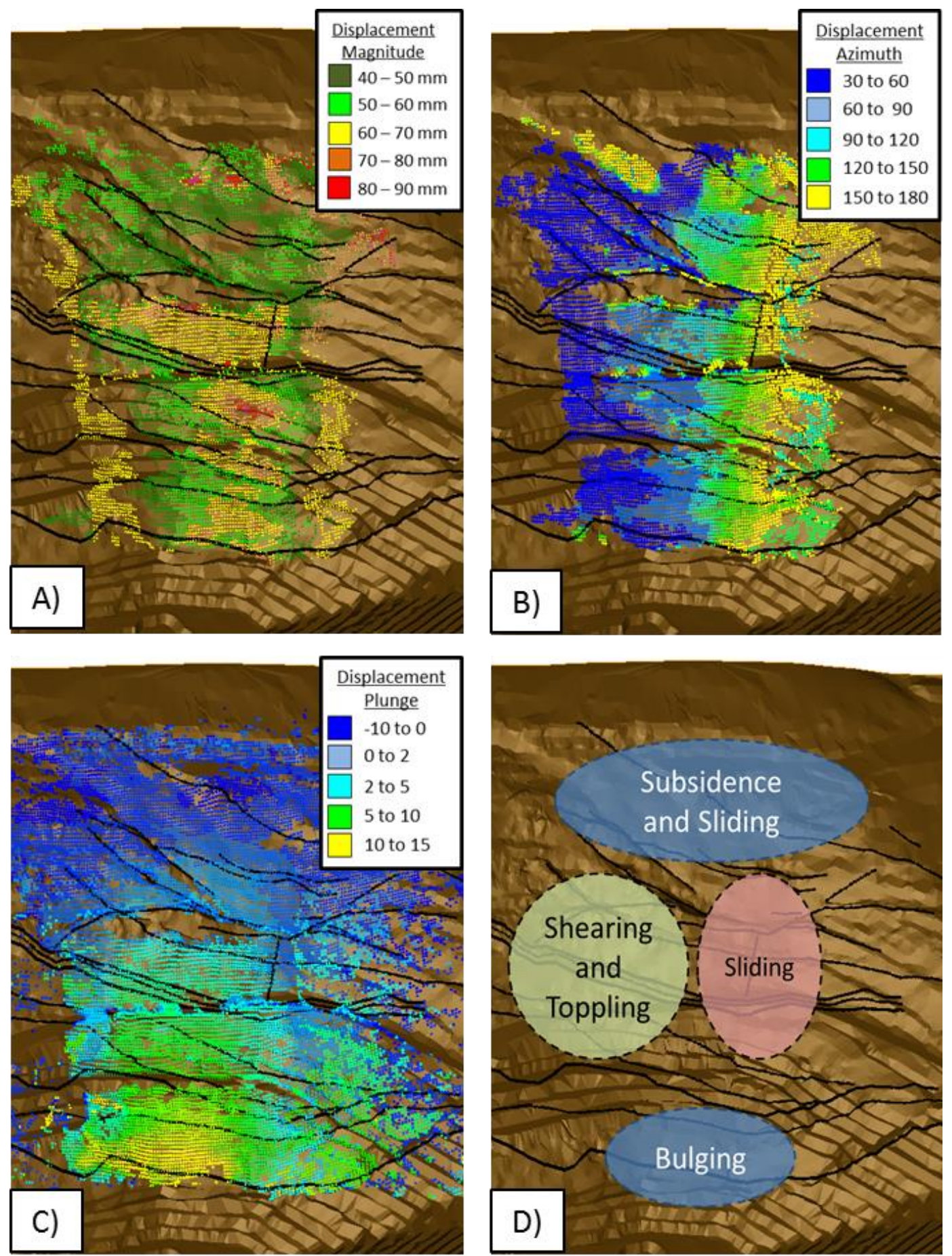

Figure 7 Oblique view of the northwest corner of the Lornex Pit, highlighting areas of higher displacement (left) and movement directions (right)

From Figure 7, the upper slope above the Lornex Fault shows higher cumulative displacements with directions ranging between 120 to $150^{\circ}$ and plunges 0 to $5^{\circ}$. Movement is interpreted as sliding controlled along a flatter dipping basal fault sub-parallel to the slope resulting in the development of graben-like blocks dropping into the space created by the translational sliding (see Figure 8). The presence of a basal fault controlling sliding in the upper slope is in agreement with the kinematic model developed by Rose and Scholz (2009). In the western half of the upper slope, these displacements decrease in magnitude and become more sporadic in terms of direction. Together they suggest that movement within this region is dominated by toppling and shearing of the rock mass. The lower line of sight displacements within the upper portion of the slope and interpretation that these are being dominated by vertical downward 
movements of graben-like blocks is supported by geodetic data that exists outside of the area focused on during the experiment. The lack of directional correlation in the 3D radar data below the LFZ suggests that the rock mass below the fault (altered Skeena Quartz Diorite) is undergoing bulging through shearing and dilation of the material. Thus the 3D radar data shows a clear and distinct difference in slope behaviour from that of the complex sliding-shearing-toppling mechanism interpreted in the upper slope. This corresponds with the presence of weaker, more tectonically disturbed rock below the Lornex Fault combined with higher shear stresses at the toe of the slope.

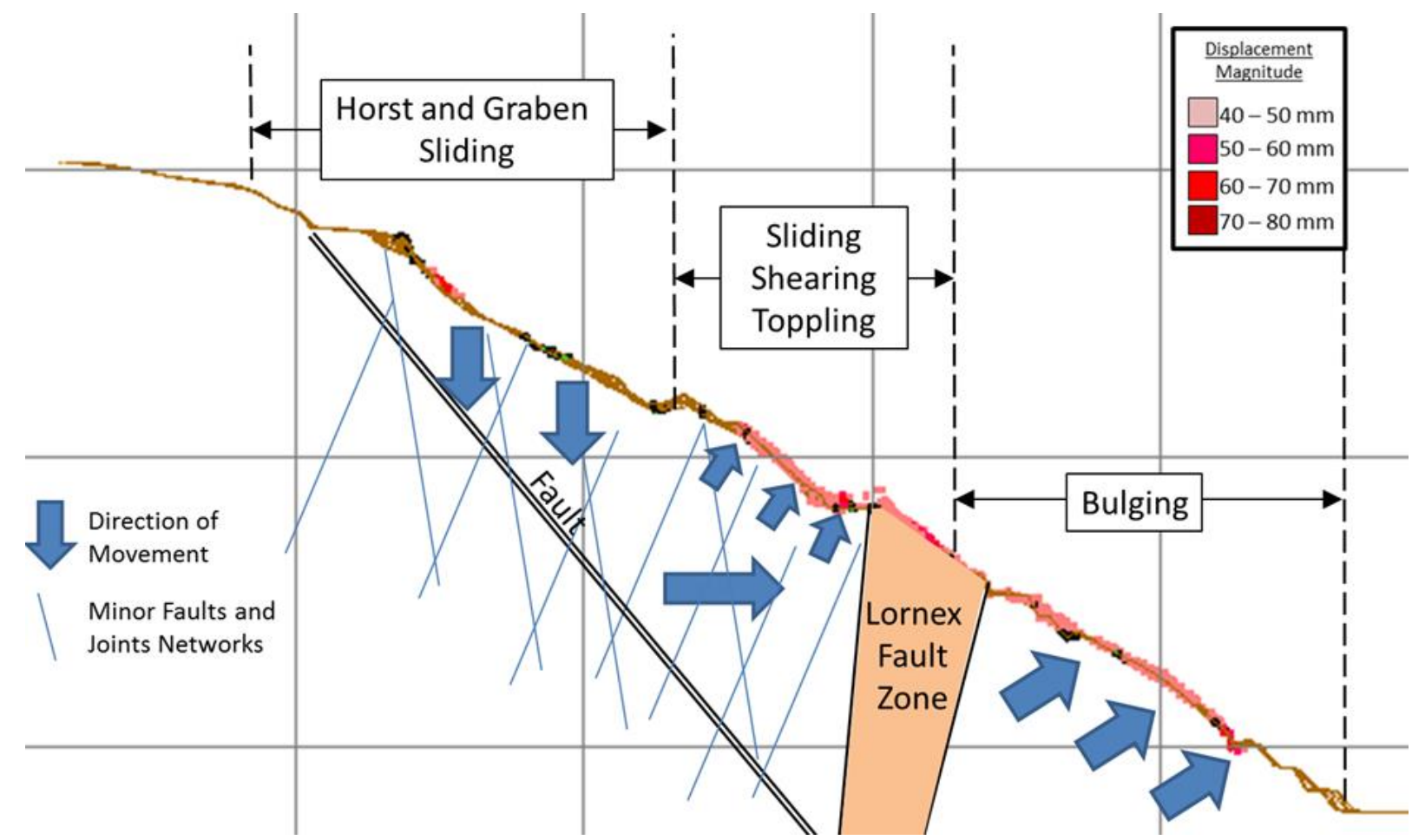

Figure 8 Schematic diagram of interpreted kinematics for the northwest wall of the Lornex Pit

\section{$6 \quad 3$ DEC model}

A pit wall scale 3D numerical model was constructed for the THVC Lornex Pit in order to confirm the complex failure mechanisms outlined above. 3DEC (Itasca, 2007), a three-dimensional distinct element code, was chosen to model this problem for its ability to represent the regions bounded by the faults as distinct blocks and allow for the rock mass to slip, separate, and rotate along the mapped structures within the pit while the individual blocks can deform and yield. Achieving the same degrees of freedom through a continuum treatment of the problem (e.g. finite-element or finite difference) is significantly more limited, especially with respect to large strain. The representation of the problem domain as an assemblage of distinct interacting blocks permitted the regions in the model to slip, open and rotate across large distances independently.

Figure 9 illustrates the 3DEC model constructed to simulate the west and north walls of the Lornex Pit. Due to the orientation of the model, displacements at the boundaries were fixed. This limits interpretation of model behaviour close to the boundaries.

The large scale structures included within the 3DEC model are illustrated in Figure 9. The base case dip direction was determined based on pit wall mapping and interpolation from the original 2D UDEC model. The damage zones associated with the Lornex Fault, W-1 Fault, and the W2-2 have been represented as 20 and $10 \mathrm{~m}$ thick zones of weaker material bounded by discrete, planar joint surfaces. All other structures have been simplified as discrete planar surfaces. 
A

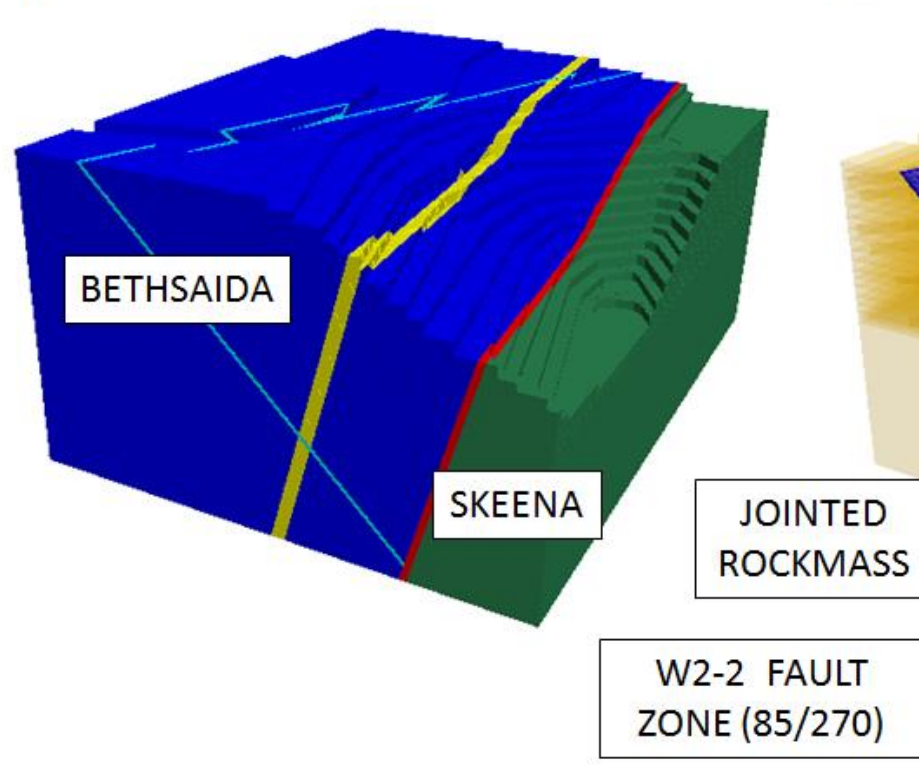

B

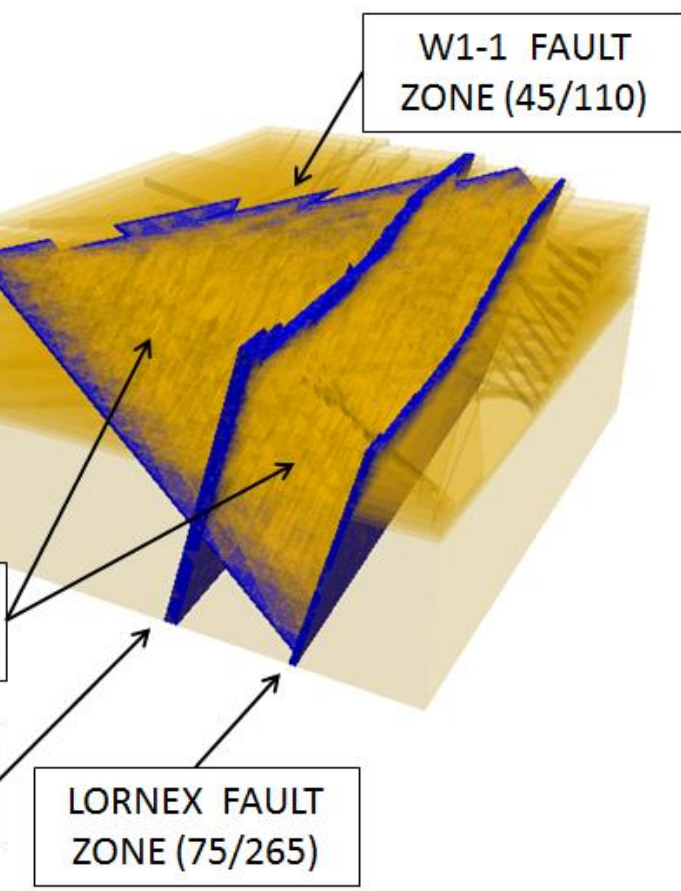

Figure 9 Large scale structures included within 3 DEC model

\subsection{Rock mass and fault properties}

The rock masses between the discontinuities within this model are assumed to behave as a homogeneous, isotropic Mohr-Coulomb elasto-plastic constitutive material. This was assigned to the individual blocks, treating them as an equivalent continuum rock mass that incorporates the strength reducing effect of the smaller scale discontinuities not explicitly included in the models. The outer most blocks in the model were modelled as elastic. The faults were assigned a Coulomb slip constitutive model. Estimates of the rock mass and fault properties were based on estimates derived from laboratory testing and field mapping data (i.e. RMR), as reported by Piteau (2008). Tables 1 and 2 present the input properties used.

Historical groundwater levels on the west wall were interpreted from drain hole flow and piezometric monitoring records and trends. Groundwater levels in the 3DEC model were simulated in five steps starting from original levels and were incrementally lowered to current conditions. In-situ stress conditions within the pit were considered to be lithostatic and generally in low-stress conditions.

Table 1 Estimated rock mass properties

\begin{tabular}{ccccccc}
\hline Model Units & $\begin{array}{c}\text { Density } \\
\left(\mathbf{k g} / \mathbf{m}^{3}\right)\end{array}$ & $\begin{array}{c}\text { Cohesion } \\
(\mathbf{M P a})\end{array}$ & $\begin{array}{c}\text { Friction } \\
\text { Angle } \\
(\mathbf{d e g})\end{array}$ & $\mathbf{R M R} / \mathbf{G S I}$ & $\mathbf{m i}$ & $\mathbf{\sigma}_{\text {ci }}$ \\
\hline $\begin{array}{c}\text { Bethsaida } \\
\text { granodiorite }\end{array}$ & 2,600 & 0.67 & 59.8 & 51 & 28 & 55.5 \\
$\begin{array}{c}\text { Skeena quartz } \\
\text { diorite }\end{array}$ & 2,600 & 0.50 & 55.2 & 43 & 28 & 37.9 \\
\begin{tabular}{c} 
Faulted rock \\
\hline
\end{tabular} & 2,400 & 0.14 & 25.2 & & & \\
\hline
\end{tabular}


Table 2 Generalised properties for major faults and joint sets

\begin{tabular}{ccccccc}
\hline Structure & $\begin{array}{c}\text { Dip } \\
\text { (deg) }\end{array}$ & $\begin{array}{c}\text { Dip } \\
\text { Direction } \\
\text { (deg) }\end{array}$ & $\begin{array}{c}\text { Cohesion } \\
\text { (MPa) }\end{array}$ & $\begin{array}{c}\text { Friction } \\
\text { Angle } \\
\text { (deg) }\end{array}$ & $\begin{array}{c}\text { Normal } \\
\text { Stiffness } \\
(\mathbf{G P a} / \mathrm{m})\end{array}$ & $\begin{array}{c}\text { Shear } \\
\text { Stiffness } \\
(\mathrm{GPa} / \mathrm{m})\end{array}$ \\
\hline Lornex Fault & 75 & 265 & 0.05 & 22 & 2 & 1 \\
W1-1 Fault & 45 & 110 & 0.05 & 22 & 2 & 1 \\
W2-2 Fault & 85 & 270 & 0.05 & 22 & 2 & 1 \\
Joint set 1 & 75 & 265 & 0.02 & 35 & 1 & 0.5 \\
Joint set 2 & 70 & 130 & 0.02 & 35 & 1 & 0.5 \\
Joint set 3 & 40 & 100 & 0.02 & 35 & 1 & 0.5 \\
\hline
\end{tabular}

\subsection{Model results and calibration}

The geometry of the 3DEC model was originally created based on the data collected from pit wall mapping and previous slope kinematic models. Using the first round of information, displacement patterns observed in the model were not consistent with the patterns observed in the radar monitoring data. In order to calibrate the 3DEC model to mimic the kinematics derived from the monitoring results, fault and joint material properties, joint persistence and dip direction of the W1-1 Fault were varied.

Within the 3D model, the W1-1 Fault dip direction was modified to both 120 and $110^{\circ}$, which were determined based on the sinuosity of the original mapping. The W1-Fault has not been conclusively mapped outside of the immediate pit area; however, the fault surface has been geologically modelled. Based on the preliminary results, a dip direction of $110^{\circ}$ for the W1-1 Fault best corresponded to the displacement pattern observed in the radar monitoring. As the fault veered away from the pit outline (i.e. dip dir. $=130^{\circ}$ or $120^{\circ}$ ), sliding was not observed within the northwest corner of the pit.

Material properties (cohesion and friction) were varied for both the W1-1 Fault and the joints. Within this series of models, the properties assigned had little effect on the observed kinematics in the model; however, the amount of movement was affected.

Base case joint persistence was initially assumed to be $100 \%$ or continuous, however, the model response to these joints indicated multiple shallow planar failures therefore joint persistence was modified to $50 \%$, $75 \%$, and $90 \%$. In the cases where persistence was changed to 50 and $75 \%$, the rock mass did not allow for the toppling behaviour to occur in the west wall. Displacement patterns for both the west wall and the northwest corner were best matched using an overall joint persistence of $90 \%$.

Displacement (vertical and horizontal) within the calibrated model of the west and northwest walls observed during the modelling exercise is illustrated in Figure 10. Figure 10(a) shows a majority of the horizontal displacement is confined to the corner of the pit which is controlled by sliding along the W1-1 Fault and parallel joints. Sliding along the non-daylighting release structure, combined with tensile failure of the rock mass to the west, causes the observed multi-bench displacement hot spots in the model. Figure 10(b) shows the confinement of the vertical displacement within the upper portion of the slope by the slope fault (W2-2A Fault). 

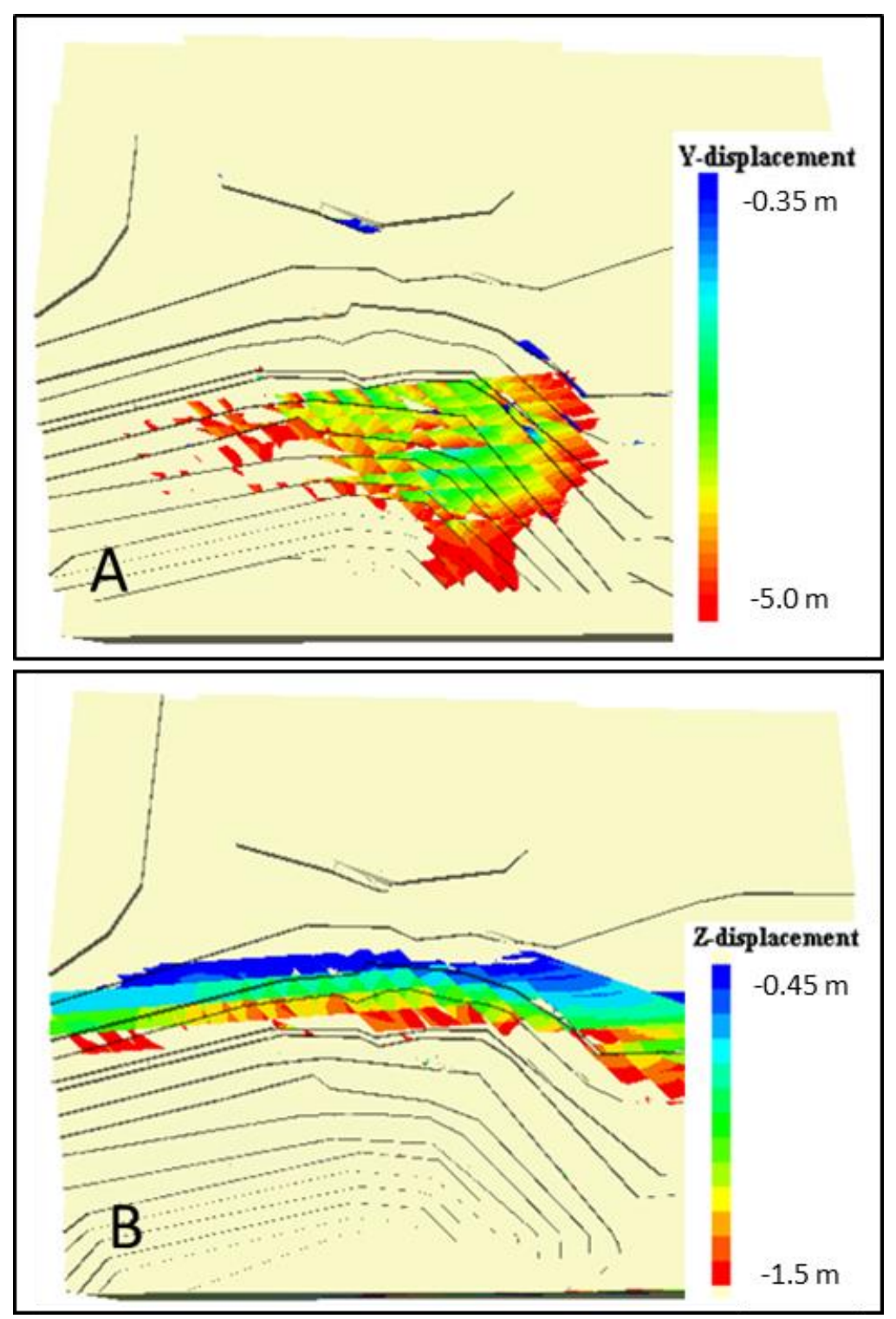

Figure 10 Plan view displacement observed within calibrated model; (a) horizontal, in primary direction of slope movement; and (b) vertical

Two sections were cut within the model, Section A, which corresponds to the northwest corner of the pit in which sliding is expected to dominate the pit kinematics, and Section B within the west wall, in which toppling is expected to dominate (Figure 11).

Figure 12 illustrates both the horizontal and total displacement results along Section A indicate a strong relationship to the underlying fault (W1-1) within the corner of the pit, which truncates along the W1-1 Fault. Displacement hot spots can be correlated to be part of a larger multi-bench displacement mechanism. Displacement along Section B, both horizontal and total, appears chaotic within the benches, with some sliding and toppling occurring along the joint sets within the slope. Displacement within the slope is controlled by the steeply dipping joint sets in the absence of the shallow dipping fault. Increased displacement was observed within the Lornex Fault Zone, as well as a generalised upward movement within the base of the slope. 


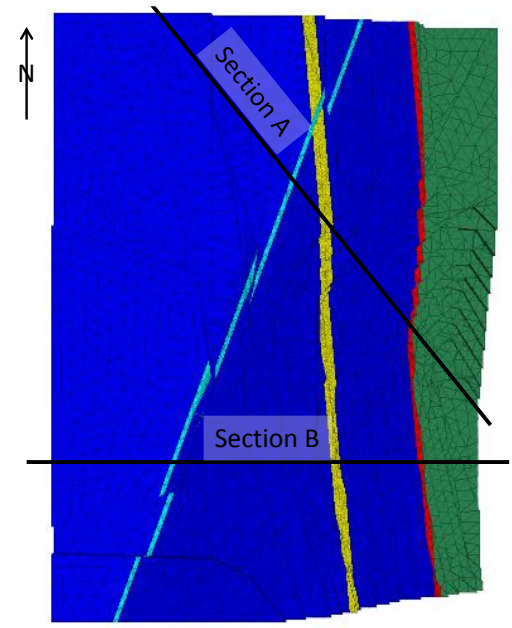

Figure 11 Location of Sections A and B, corresponding to areas of dominated by sliding and toppling, respectively
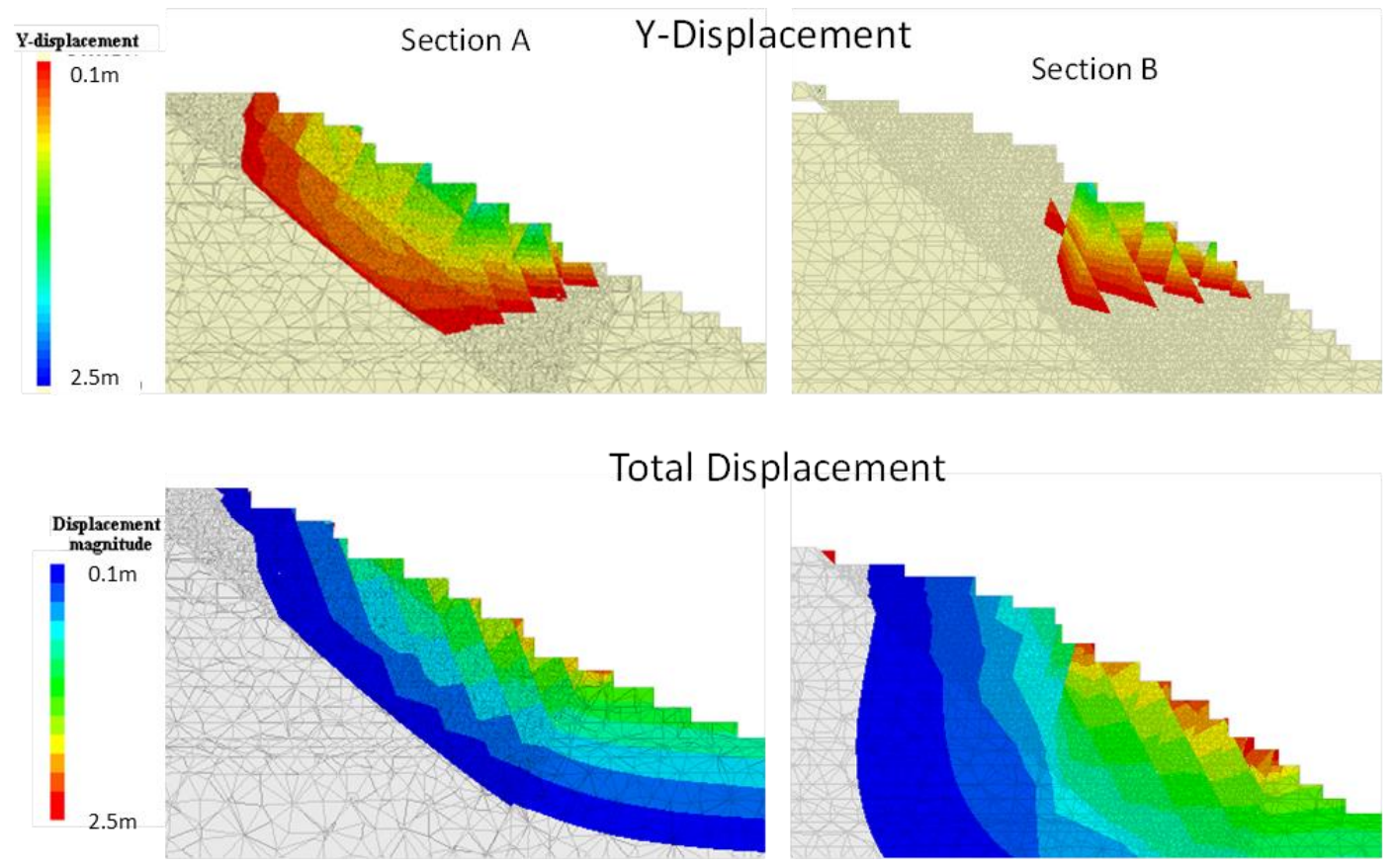

Figure 12 Horizontal and total displacement patterns within section A and B of the ${ }_{3} D E C$ model

\section{Conclusions}

A novel experiment involving the simultaneous deployment of two ground-based radar systems was conducted to collect continuous, line of sight displacement data in 'stereo' of a large, moving open pit slope bisected by a large fault. The simultaneous monitoring with two synthetic aperture radar units has led to the construction of a high resolution, pseudo-3D displacement map of a large open pit rock slope. Analysis of the corresponding displacement vector map allowed an interpretation of the overall slope kinematics to be resolved. The 3D radar experiment was able to identify localised movements related to smaller scale geological structures and changes in pit wall slope orientation.

The previous understanding of slope kinematics was significantly improved by using the pseudo 3D radar data and adds even further value to a mine project where the mine plan is considering a pit wall pushback to deepen the pit. In this case, the influence of the controlling nature of the major faults and smaller structures on north west pit wall movements can be investigated and better understood with respect to pit 
geometry, slope deformation kinematics, evolving failure mechanisms, and ultimately geo-risk, to then be projected for future deepening of the pit and pushback of its slopes.

Understanding of the 3D slope kinematics has allowed for a calibration of important fault and joint properties (including location, persistence and strength) used within the 3D numerical model. A controlling factor on calibrating the model to achieve similar displacement patterns as observed within the monitoring data was the location of the primary fault structures and the persistence of the lower priority joint sets. Once a similar displacement pattern had been achieved, the joint strength properties were modified to create comparable magnitudes of displacement.

Two controlling properties that required calibration within the numerical model were: 1) Fault orientation (i.e. dip, dip direction, and irregularity) and 2) Joint persistence within the model. Results from the sensitivity analysis of the dip and dip direction of the faults confirmed that the slope kinematics observed in the pit wall is influenced by the intersection angle between the pit wall and the fault. At dip directions more than $15^{\circ}$ variance from $110^{\circ}$, the amount of sliding observed in the model was severely affected. Characterisation of the Lornex Fault Zone and the W1-1 Fault also influenced the distribution of observed displacement within the model. In an example where a complex fault shape with several irregularities was used, localised sliding occurred within the wall. Variance in joint persistence affected the magnitude, location, and mechanism of the failures observed within the models. Regions of higher joint persistence showed higher displacement magnitudes with decreased displaced area. In turn, in models with lower persistence in the joints ( $80 \%$ to $90 \%$ ), a larger area of the pit wall deformed.

\section{Acknowledgement}

The authors thank Teck Highland Valley Copper for providing access to the mine site, logistical support, and mine data for the experiment. The authors would also like to thank Ingegneria Dei Sistemi (IDS) for personnel and technical support as well as the use of the second IBIS-M radar unit for this experiment. Funding for this experiment was provided by Teck Highland Valley Copper and a British Columbia Innovation Council Natural Resources and Applied Sciences (NRAS) Endowment grant.

\section{References}

Brummer, R., Li, H. and Moss, A. (2006) The transition from open pit to underground mining: An unusual slope failure mechanism at Palabora, in Proceedings Stability of Rock Slopes in Open Pit Mining and Civil Engineering Situations, Johannesburg: SAIMM, pp. 411-420.

Day, A.P. and Seery, J.M. (2007) Monitoring of a large wall failure at Tom Price Iron Ore Mine, in Proceedings International Symposium on Rock Slope Stability in Open Pit Mining and Civil Engineering (Slope Stability 2007), Yves Potvin (ed), 12-14 September 2007, Perth, Western Australia, Australian Centre for Geomechanics, Perth, pp. 333-340.

Farina, P., Leoni, L., Babboni, F., Coppi, F., Mayer, L., Coli, N. and Thompson, C. (2012) Monitoring Engineered and Natural Slopes by Ground-based Radar: Methodology, Data Processing and Case Studies Review, in Proceedings SHIRMS 2012, SAIMM, p. 10.

Fukuzono, T. (1985) A new method for predicting the failure time of a slope, in Proceedings 4th International, Conference and Field Workshop on Landslides, Tokyo, Tokyo University Press, pp. 145-150.

Harries, N., Noon, D. and Rowley, K. (2006) Case studies of slope stability radar used in open cut mines, in Proceedings Stability of Rock Slopes in Open Pit Mining and Civil Engineering Situations, Johannesburg, SAIMM, pp. 335-342.

Harries, N.J. and Roberts, H. (2007) The use of slope stability radar (SSR) in managing slope instability hazards, in Proceedings Rock Mechanics: Meeting Society's Challenges and Demands, E. Eberhardt, D. Stead and T. Morrison (eds), 1st Canada-US Rock Mechanics Symposium, 27-31 May 2007, Vancouver, Canada, Taylor \& Francis, London, pp. 53-59.

Itasca Consulting Group Inc. (2007) 3DEC version 4.1, 3 Dimensional Distinct Element Code.

Piteau Associates Ltd. (2008) Open Pit Geotechnical Assessments and Preliminary Slope Design Criteria for the Lornex Pit L16 Expansion, Internal Document.

Rödelsperger, S., Läufer, G., Gerstenecker, C. and Becker, M. (2010) Monitoring of displacements with ground-based microwave interferometry: IBIS-S and IBIS-L, Journal of Applied Geodesy Vol. 4(1), pp. 41-54.

Rose, N. and Scholz, M. (2009) Analysis of complex deformation behaviour in large open pit mine slopes using the Universal Distinct Element Code (UDEC), in Proceedings International Symposium on Rock Slope Stability in Open Pit Mining and Civil Engineering (Slope Stability 2009), Santiago, Chile, 9-11 November 2009, CD-Rom, 11 p.

Severin, J., Eberhardt, E., Leoni, L. and Fortin, S. (2011) Use of Ground-Based Synthetic Aperture Radar to Investigate Complex 3-D Pit Slope Kinematics, in Proceedings International Symposium on Rock Slope Stability in Open Pit Mining and Civil Engineering 2011 (Slope Stability 2011), September 18-21 2011, Vancouver, Canada, USB format. 
Tosney, J.R., Milne, D., Chance, A.V. and Amon, F. (2004) Verification of a Large Scale Slope Instability Mechanism at Highland Valley Copper, International Journal of Surface Mining, Reclamation and Environment, Vol. 18, No. 4, pp. 273-288. 